\title{
INTEGRATED MONITORING SYSTEM OF PRODUCTION PROCESSES
}

\author{
Przemysław Oborski \\ Warsaw University of Technology, Institute of Manufacturing Technology, Poland
}

Corresponding author:

Przemystaw Oborski

Warsaw University of Technology

Institute of Manufacturing Technology

Narbutta 86, 02-524 Warszawa, Poland

phone: (+48) 22 234-86-55

e-mail: p.oborski@wip.pw.edu.pl

Received: 17 November 2016

\section{ABSTRACT}

Integrated monitoring system for discrete manufacturing processes is presented in the paper. The multilayer hardware and software reference model was developed. Original research are an answer for industry needs of the integration of information flow in production process. Reference model corresponds with proposed data model based on multilayer data tree allowing to describe orders, products, processes and save monitoring data. Elaborated models were implemented in the integrated monitoring system demonstrator developed in the project. It was built on the base of multiagent technology to assure high flexibility and openness on applying intelligent algorithms for data processing. Currently on the base of achieved experience an application integrated monitoring system for real production system is developed. In the article the main problems of monitoring integration are presented, including specificity of discrete production, data processing and future application of Cyber-Physical-Systems. Development of manufacturing systems is based more and more on taking an advantage of applying intelligent solutions into machine and production process control and monitoring. Connection of technical systems, machine tools and manufacturing processes monitoring with advanced information processing seems to be one of the most important areas of near future development. It will play important role in efficient operation and competitiveness of the whole production system. It is also important area of applying in the future CyberPhysical-Systems that can radically improve functionally of monitoring systems and reduce the cost of its implementation.

KEYWORDS

production process, integrated monitoring systems, Cyber-Physical-Systems, management systems, process monitoring, shop floor control, company IT systems, multiagent systems.

\section{Introduction}

Continuous development of products is based on adding new, more complex functionality, increasing quality and simplification of use. Completely new products based on new materials, algorithms and connecting of traditional mechanical solutions with information processing are introduced into the market more often than in the past. They are produced in shorter batches, very often on client request and according to specific demand [1]. Products time on the market is rapidly reduced as well, so more often modifications and new solutions have to be intro- duced [2]. Those factors require continuous development of production processes. Integration of information flow in the whole production system including manufacturing became one of the most important areas of development. Integrated management systems are standard solutions on the management level [3]. On the manufacturing level integration of machine tool control and process condition monitoring systems with Shop Floor Control still is a vision of future [4]. Implementation of advanced monitoring systems usually is limited to standalone solutions that are focused on supervision of selected processes or machines. They are not integrated into one system, 
so it is impossible to perform advanced analysis, like complex verification of products quality or archiving its production history. Integration of production process become especially important in the age of rapidly developing Internet-based applications, cloud computing, etc. It allows for the integration of company IT systems into the supply chain management system [5]. Such a solution should include integration of Shop Floor Control and monitoring of production processes [6].

\section{Cyber-Physical-Systems in monitoring}

Wide applying of integrated monitoring systems strongly depends on development of inexpensive, flexible cyber-technical solutions that can be implemented in machines, tools or even products. Such solutions have to connect advanced computing systems, monitoring devices and intelligent software applications. They have to be easy to configure and implement closely to machining process. Future advanced embedded technology called Cyber-PhysicalSystems (CPS) probably would be the base for development of such solutions. According to NSF definition Cyber-Physical-Systems are engineered systems that are built from, and depend upon, the seamless integration of computational algorithms and physical components [7]. Cyber-Physical-Systems are the next generation of embedded systems that can be used in different areas of production machines and processes.

Comparing to embedded systems that are currently in use, advanced CPS should enable much higher capability, adaptability, scalability, resiliency, safety, security and usability. The future appli- cations of CPS can be more transformative than the IT revolution in the past, as many researchers points [8]. Unparalleled analytical capabilities, possibility of joining sensors, controllers and micro mechanical solutions with intelligent real-time computing of networked information will create new opportunities for systems integration. Probably next generation CPS will be able to execute extraordinary tasks that are barely imagined today [9]. Cyber-PhysicalSystems technology is comparable to the way that smartphones changed communication between people and interaction with Internet. They will transform the way people and IT applications interact with technical systems. Solutions operating similarly to smartphones should allow performing number of parallel process containing: data collection, advanced processing and problems solving. New smart CPS should drive innovation into number of areas of manufacturing systems. Monitoring and control will be one of the most important places changed by them. The most important expectations of their application arise from possibility of increasing functionality, miniaturization, effective integrating technical and cyber functions, implementation of embedded MEMS solutions, easy programming and application. It will also allow for radical reduction of implementation cost of mart technical solutions. CPS computational intelligence in the area of monitoring can be used for well-defined tasks and processes, especially when demands or constraints don't need human intervention. Very promising can be also connecting sensors, real-time data processing, intelligent decision taking and communication into one industrial environment resistant solution implemented closely to monitored devices or process.

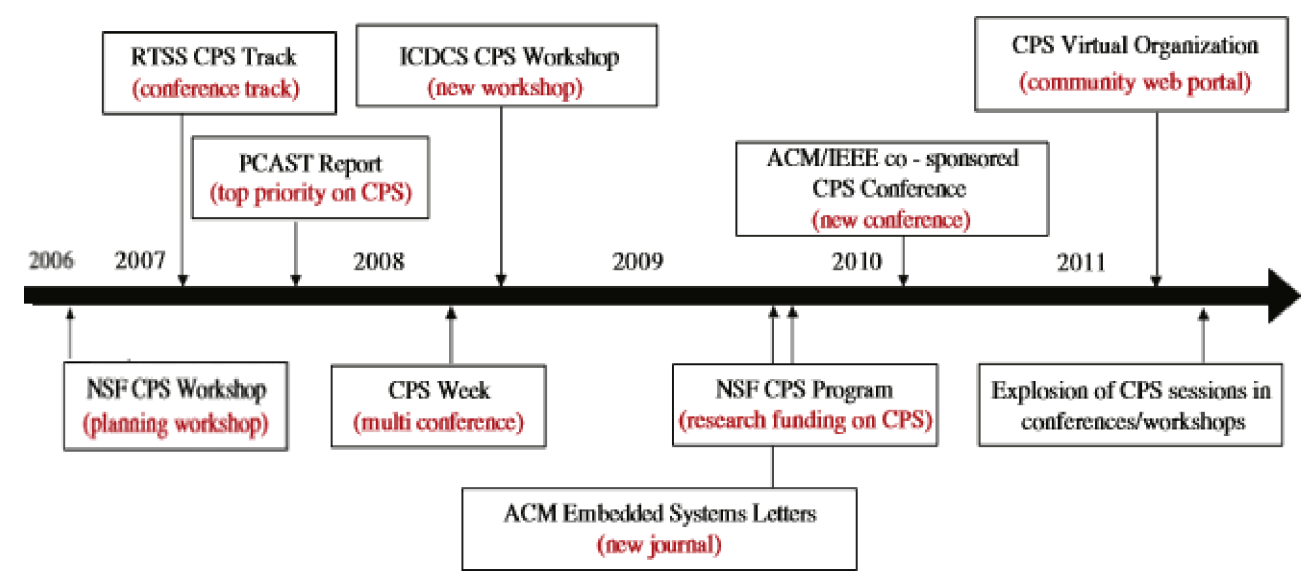

Fig. 1. Cyber Physical Systems timeline [8]. 


\section{Development in manufacturing systems}

Manufacturing systems development is based on advances in production process, machines, materials and control devices. Effective management of more and more complex and sophisticated systems requires improving of an integration level. It has to be done on different levels of the system: technical, IT applications, business processes and production process [10]. Applying an intelligent components in control and monitoring of machines and processes is one of the most important directions of modern manufacturing systems development.

An idea of Cyber Physical Systems and Smart Manufacturing will play an important role in improvement of production systems. One of the most difficult problem in the production area is an integration of information management on all levels of the production system. Production process usually is performed in geographically distributed different plants. In this situation the organization of production processes, usually based on philosophy of Lean Manufacturing, has to be supported by fully integrated IT systems [11].

However, one of the most difficult is integration of IT systems with control and monitoring of particular machines and machining processes. IT systems should process on-line information about particular product and its parts manufacturing. Such information especially from machining, like process and machine parameters, tool condition, vibrations, machine distortion's, temperature, part geometrical dimensions, structure of part material, etc. should be accessible on request and archived. Remote online access to production data would allow for much more efficient management of all production process and supply chain as well [12]. Recording of such a data could allow for keeping a history of particular products and its parts manufacturing. Such history would allow for easier fulfilment of quality requirements and for more efficient life cycle management of product and its parts [13].

\section{Monitoring in advanced manufacturing}

Monitoring is an important part of advanced manufacturing systems. It should play a crucial role in ensuring agility of manufacturing system and efficiency of control and management [14].

Growing requirements on process robustness, responsiveness to client demands, and achievement of a sustainable production environment require application of more advanced and integrated monitoring systems. General idea of monitoring system integration was presented by Leitao - see Fig. 3. Realisation of such idea was based of dedicated IT systems. As a result it was very complicated, inflexible and expensive. In practise integrated monitoring systems were applied only in fully automated system called Flexible Manufacturing Systems. Moreover, such systems had in practice very limited functionality focused in practice on general supervision of proper machine operation and order performance. In most

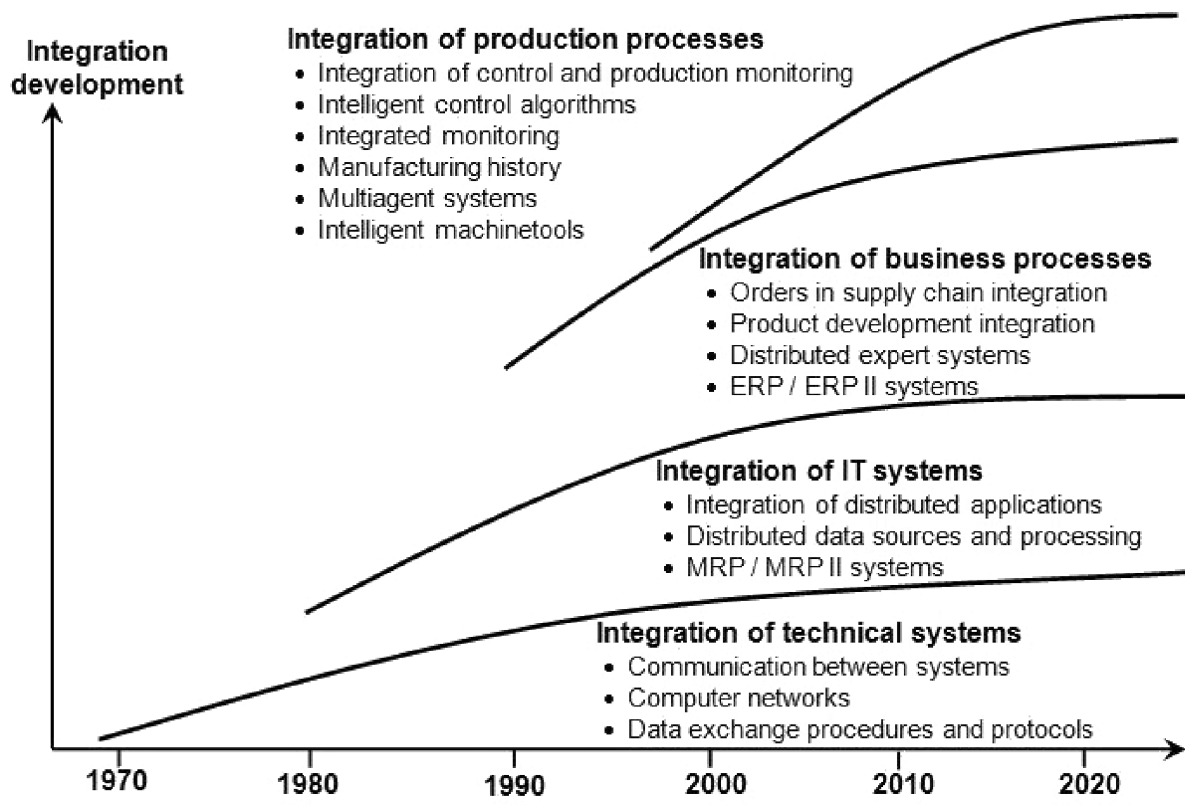

Fig. 2. Development of integration in manufacturing systems (on the base of [6]). 


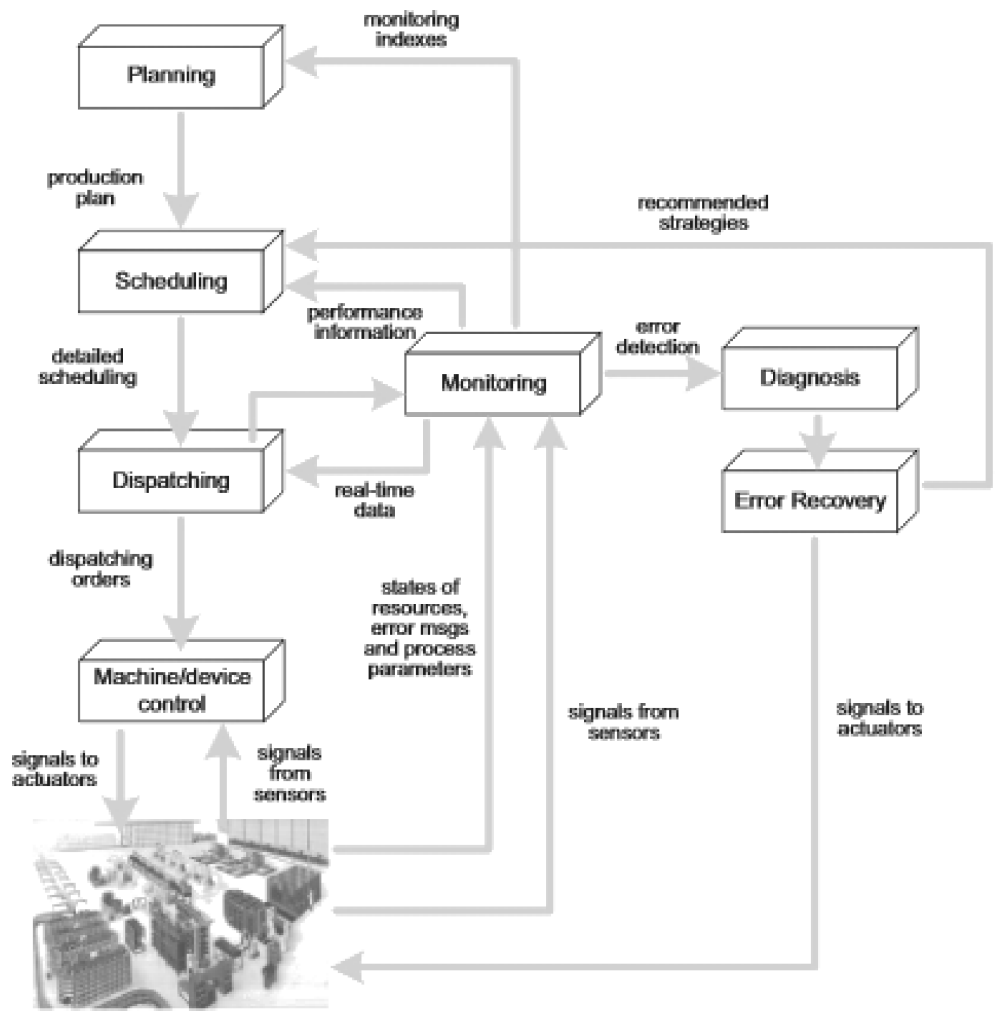

Fig. 3. General model of control and monitoring in Flexible Manufacturing System [17].

manufacturing systems a feed-back information is limited to paper based reporting about production progress without possibility of process and machine condition monitoring and advanced on-line data processing.

Currently most research on highly advanced monitoring is focused on standalone solutions that don't form one complex system as shown in reviews done by Oborski [4], Byrne et al. [15] and Teti et al. [16]. Future monitoring applications will have to be fully integrated with company IT systems. A local applications focused on monitoring of particular process, machine parts, or products features should be integrated into one homogenous system. It should allow for easy information flow between machining process level and management IT systems.

New opportunities for integration of monitoring systems are opened by developments in computer technology and data processing, as well as solutions and advances in programming technology. Rapid development in the area of IT systems and solutions, like cloud computing, allows currently for the practical implementation of monitoring integration into distributed Internet based systems [4]. Integrated advanced monitoring systems should support production and supply chain management, as well as optimisation of production processes. Deci- sion process performed by advanced control systems could be supported by information from evaluation of product quality based on an analysis of monitored manufacturing parameters. Product lifecycle management could be supported by history of particular parts manufacturing, including recorded machining processes, machines parameters and results of their analyse [18].

Research on integration of various standalone monitoring applications have to be suited into particular systems specific properties. Integration of monitoring functions in process industry generally is relatively easy to do. It is based mainly on dedicated systems developed in advanced SCADA environment [19]. However, in discrete production, like manufacturing and especially milling or cutting, integration of monitoring functions into one system is much more difficult. It requires performing large amount of highly changeable data and taking into account a structure of a particular products and manufacturing process. A data acquisitioned by sensors and specialized systems have to be processed by dedicated advanced, and very often intelligent algorithms. Very often measurement frequency have to be extremely high like in the case of Acoustic Emission (AE).

Most of signals require preprocessing to eliminate various kinds of noise. Finally advanced processing 
is needed to achieve an information about monitored process condition - see an example in Fig. 4. On the base of it artificial intelligence algorithms can take decisions about process status and appropriate actions [4].

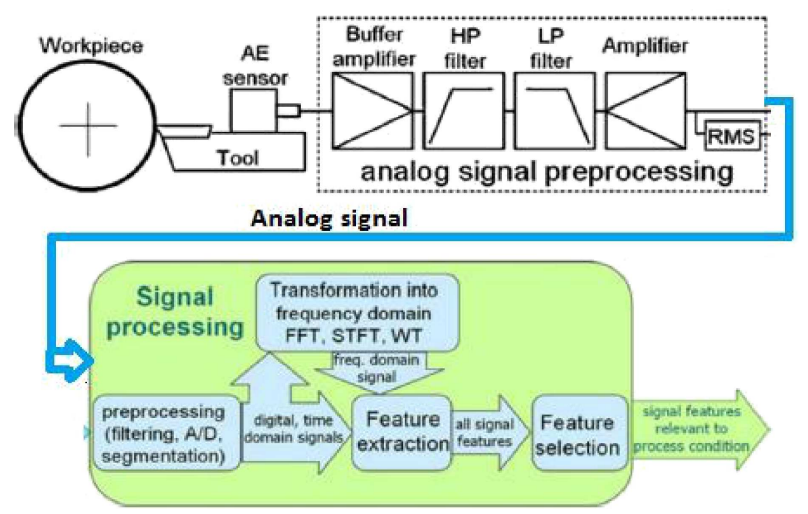

Fig. 4. An example of advanced signal processing in a monitoring of cutting process ([4] - based on Teti et al. [16]).

Future development of signal acquisition and processing applications should be based on easy to configure Cyber-Physical-Systems. Currently used monitoring applications are built on the base of advanced signal processing computer cards and dedicated expensive hardware. It is too expensive for common use in mass production. Dedicated solutions built on traditional embedded systems are not flexible enough, and their application is too complicated. Future monitoring devices have to be based on Cyber-Physical-Systems, that should be inexpensive, easy for configuration and implementation, similarly to smartphones in business and private life [9]. Application of CPS technology into monitoring of machining processes, machines and produced parts would allow for efficient information acquiring. Efficient utilization of information from future monitoring systems will need highly advanced IT systems. They should be flexible, efficient, open for reconfigurations and able to work with large amount of data in production environment. Current IT systems based on client-server technology generally don't meet those requirements.

\section{Research on advanced integrated monitoring systems}

Detailed review of advances in manufacturing systems monitoring [4] shows need of new approach development in the area of integration of various monitoring applications. Advanced monitoring solutions based on innovative signal processing, minia- turized multifunctional sensors and artificial intelligence allows for more and more efficient supervision of manufacturing process. Development in area of Cyber-Physical-Systems will allow for easier and cheaper implementation of advanced monitoring in machines and production systems [20]. However, as review shows there is still lack of research on the advanced, flexible and easy to use IT solutions that will allow for integration of various monitoring applications into one homogeneous system.

The research presented in the paper aimed to change this situation. The conception of practical realization of the integrated monitoring system was developed. The reference models were proposed as a practical description of discussed idea. Their correctness was verified by development and testing the integrated monitoring system demonstrator.

Models, conceptions and standards based on research verified by demonstrators validation are necessary for development of all kinds of complex systems [21]. Reference models describing a structure and conception of the system are necessary at the beginning of particular area development. They have to be a kind of recommendation for researchers by describing a general idea of the problem solving. Standards are necessary in the next step of systems development and implementation. They are important for supporting of different research teams in development of their applications based on individual approaches, various technical solutions and implemented in various environments.

The research presented in the paper were focused on development of the idea of integrated monitoring systems and reference models. In the next step a demonstrator was built to verify taken assumptions. Research has been focused on three main directions: 1. Reference models of integrated monitoring systems.

2. Data management and data reference models.

3. Development of various demonstrators of integrated monitoring systems.

Detailed information about all three directions are presented in the following chapters.

\section{Reference model of integrated monitoring systems}

General description of integrated monitoring systems was proposed in the form of multilayer reference model. Tasks performed by technical systems like: sensors, monitoring devices, and software modules responsible for signal processing, deduction, decision taking, data archiving and cooperation with management IT systems, were ordered in separated 
Management and Production Engineering Review

layers. Every layer is responsible for performing specific tasks. It is based on different hardware systems and use different software solutions. A general view of the multilayer reference model of integrated monitoring system is presented in Fig. 5.

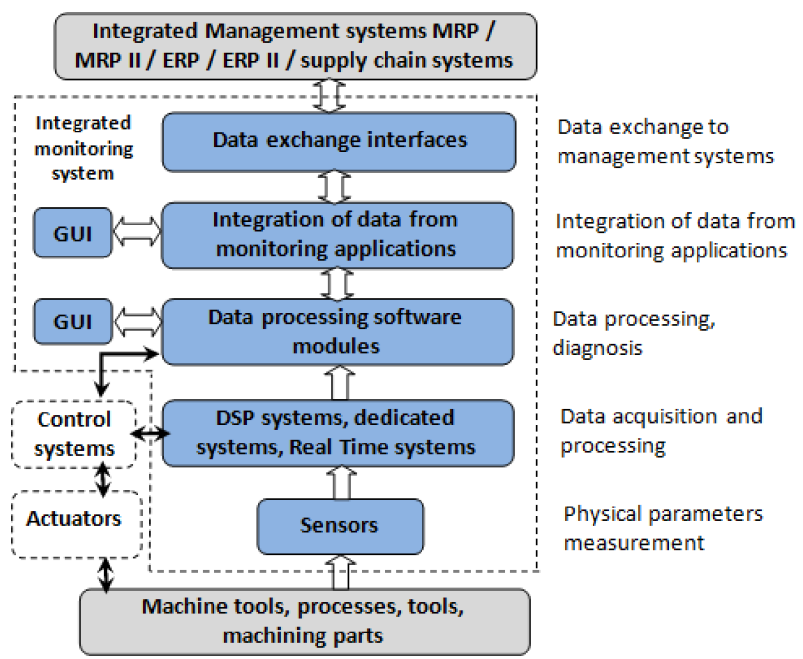

Fig. 5. General concept of multilayer reference model of integrated monitoring system for manufacturing process.

The aim of the model is to order tasks necessary to perform on various levels of integrated system. The first layer is responsible for measurement of physical signals - it contains sensors. The second layer is responsible for signals acquisition and processing. The first and second layers in the future should be based on advanced Cyber-Physical-Systems. The third layer is responsible for data processing and diagnosis of problems.

The fourth layer is responsible for integration of monitoring data and diagnosis, presentation of data for machine operators and supporting a decisions taking. Together with the third layer it should be based on panel computers installed close to machine and process. On that level open, intelligent and easy to reconfigure software can integrate also identification of manufactured parts, identification of production documents, operators support and geometrical measurement of the part. The last, fifth layer is responsible for integration of the monitoring systems with IT management systems. The order structure as well as production process information and data should be transferred into integrated monitoring system. Data and information about status of particular orders, process conditions, identified problems, diagnosis and taken decisions processed and collected by monitoring system have to be available for all interested players. It should be available for people and systems working on the management level, designee, process planning and supply chain. In the fu- ture a standards of the tasks performing, and dedicated technical solutions, also on the base of future Cyber Physical Systems, has to be developed.

\section{Multilayer reference model of data integration}

One of the key problems in the integration of monitoring systems is processing of acquisitioned data and its ordering according to product and manufacturing process structure. Research were focused on graphs theory and in this on data trees. Finally eight layer data tree reference model was proposed, it is shown in Fig. 6. Each of them is responsible for particular data collecting. Every kind of data is saved in dedicated, clearly described level of the model. A monitoring data saved at the lowest levels is joined to upper levels. They describes explicitly a moment of a machining when monitoring data was registered as well as part, product and order it relates. The first level contains data from monitoring. It can be raw data or in the case of high frequency of probing, like in the case of Acoustic Emission, an information prepared by dedicated real-time subsystems, based for example on of Cyber-Physical-Systems. The second level allows for saving decisions taken during processing of monitoring data. The third level keeps information about monitored parameters.

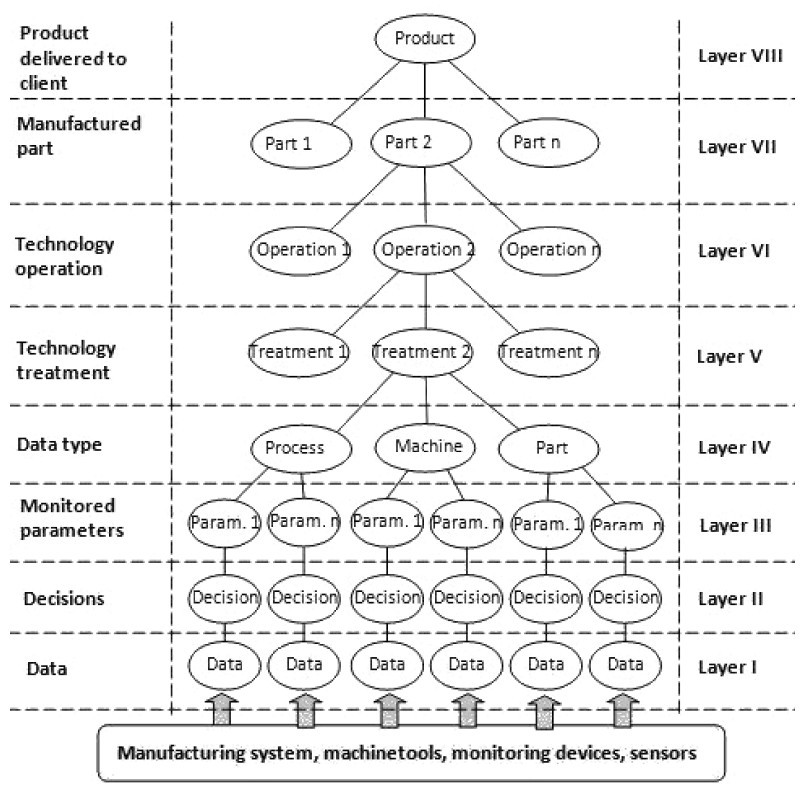

Fig. 6. Multilayer reference model of data integration for manufacturing process monitoring system.

The fourth level allows to distinguish monitoring area. The fifth level describes specific manufacturing process treatment performed one surface by one 
tool with particular set of parameters. The sixth level saves information about manufacturing operation performed on one machine by different tools on different surfaces. The seventh level saves information about particular work piece. The last level assigns information to particular product.

Proposed model allows for ordering information obtained from distributed monitoring devices and applications. It allows for arranging data into logical, hierarchical structure assigned to structure of manufacturing process and product. According to particular needs models can be simplified by joining together selected levels. Multilayer data model should be implemented in the data base of integrated IT system responsible for production process monitoring. IT Systems operated on management level, like MRP/ERP, MES systems or dedicated systems responsible for product data management should cooperate with it. The simplest way of cooperation will base on importing of orders data from MRP/ERP system for eight and seventh level of the model. A data for sixth and fifth level can be imported from process data management systems. A data in the levels from one to fourth is prepared by integrated monitoring system by its proper modules. The best solution would be extension of MRP/ERP systems data bases by proposed multilayer data model. It would allow for easy management, on the company level, of data fully describing the history of whole production process of particular parts.

\section{Demonstrator of multiagent integrated monitoring system}

The demonstrator of integrated monitoring systems built in the research is based on proposed multilayer models. It aim is to validate proposed solutions. The demonstrator has a multilayer structure where every layer is responsible for performing specific tasks, appropriately to proposed model. Various IT technologies were used to implement integrated monitoring systems. The system core is built on the base of multiagent technology that allows for developing flexible and easy to reconfigure systems. Applying this technology into some monitoring solutions was tested by Desforges [22], Mangina [23] and Liu [24]. Multiagent system is consist of intelligent objects - agents. Every agent can independently solve its tasks using its own algorithms [25]. Intelligent algorithms can be easily implemented in agents. Every agent is responsible for solving its tasks and related problems. Agents to perform systems goals cooperates each other according to implemented algorithm. Multiagent technology allows for building intelligent systems that are open for reconfiguration and are more robust on malfunctions and disruptions then the traditional systems based on client-server architecture [26].

Agent technology has been chosen for demonstrator implementation because of necessity of high robustness, openness on reconfigurations and easy implementation of various also intelligent algorithms in the system. Agent application is supported by software build in client-server technology. A graphical interface, database and system responsible for data management are based on client-server technology. The general UML model of built multiagent integrated monitoring system is shown in Fig. 7.

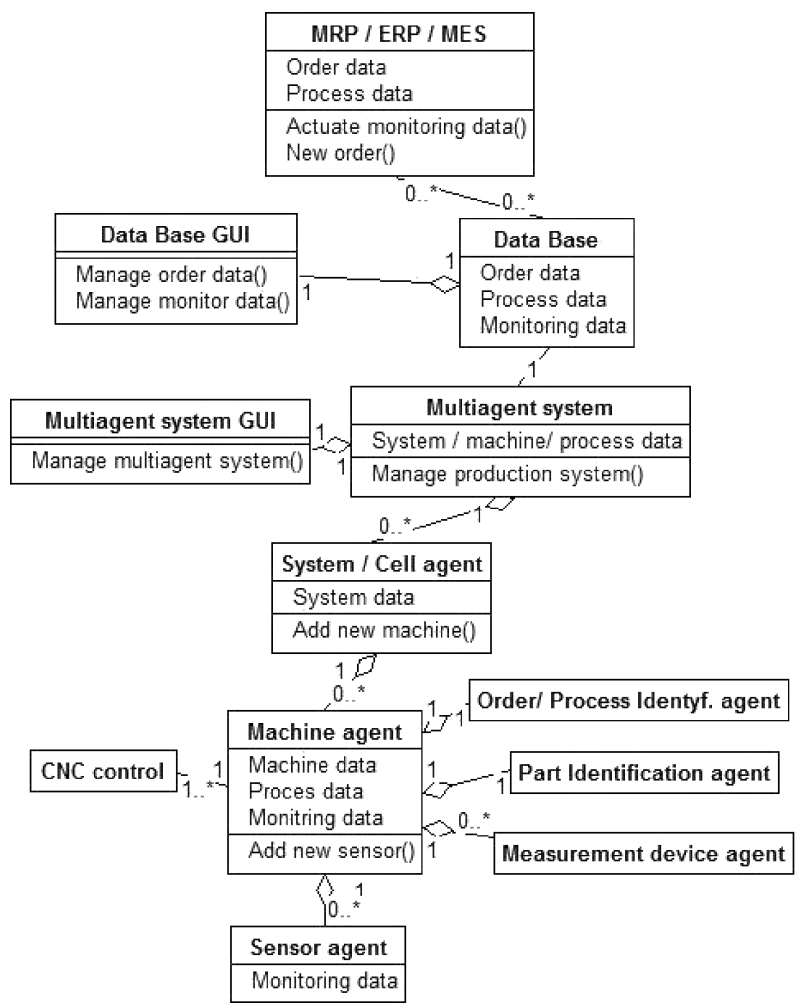

Fig. 7. General UML model of multiagent integrated monitoring system.

The lowest level of the demonstrator is based on specialized monitoring applications responsible for highly changeable signals acquisition and processing. They works according to constrains of Hard Real Time systems [27]. Such applications and PLC controllers responsible for acquisition of signals with lower frequency of probing, as well as drivers for collecting signals directly from sensors are connected to sensors agents. Sensor agents are responsible for management of data and information gained by particular sensors. Data and information can be acquisitioned from specialized measurement applications or 
Management and Production Engineering Review

directly from sensors. Using dedicated intelligent algorithms sensor agents should identify problems and undertake decisions about proper actions. In the future Cyber-Physical-Systems should be applied for signals acquisition and its processing. CPS would allow for application micro multifunctional sensors, signals acquisition and processing software, together with sensor agent responsible for autonomous management of monitoring data.

Machine agents are in the next level of integrated monitoring system. Their role is integration on the machine level a monitoring information from various sensor agents. A processing of it is performed and decisions can be made. Machine agent can integrate also agents responsible for control machined part identification systems. A system for order and/or performed process identification can be implemented on that level as well. Identification can be done by barcode scanners or other identification systems. Also a data from measurement devices can be collected on the machine level agent. It will allow for integration of machine operators tasks with the company IT system. The next level of the monitoring system is a system agent that integrates various machine agents. Advanced, further processing of monitoring data and information can be done on that level. An assessment of the quality of particular parts and fulfillment of order requirements can be done on the base of information from the whole manufacturing process.

Next levels consist of application for multiagent system management, system data base, Graphical User Interfaces (GUI) as well as interfaces to integrated management systems (MRP/ERP). Those levels are built on the base of client-server technology. An important part of this part of the systems is data management and storage. It has to be done according to requirements of proposed multilayer reference model of data integration.

Integrated monitoring systems should work without human interventions [28]. However, it should offer possibility to integrate machine operator into information flow [29]. The system demonstrator was built to tests the idea of proposed models. Examples of the application screens are showed in Figs. 8 and 9.

The demonstrator interface offer information supporting operator and allow for easy data entering to the system. Implementation of such kind of a system requires proper design of the communication process with human operators taking into account social-technical aspects and it influence on machine operators work [30, 31].

Developed system based on multiagent technology use two kinds of data base. The first one operates

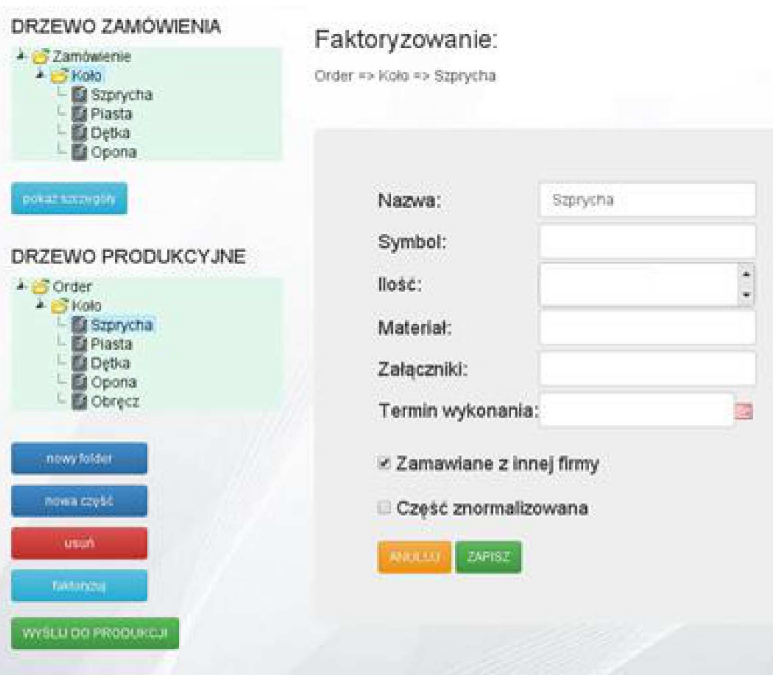

Fig. 8. Example of the system GUI screen - setting order and data entering.

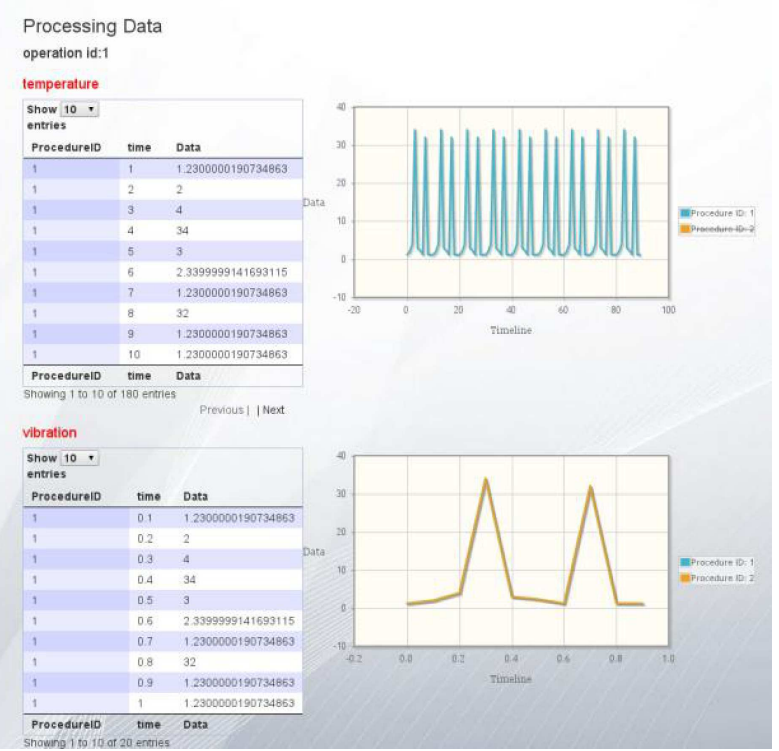

Fig. 9. Example of the system screen - presentation of data from process monitoring.

on the level of machine agent. It is based on open, nonrelation data base built in MongoDB technology. Every agent has its own database that allows collecting and performing data from monitoring of machining process, machine and produced part. A data is saved in the JSON format that allows for quick saving and analyzing data from sensors agents. The next data base is based on SQL structure that allows for easy saving relations used in data based implemented on company management level. It allows for communication with integrated company systems like MRP/ERP, MES or systems for supply chain management. The SQL data base can import orders data from MRP/ERP systems. A data from inte- 
grated monitoring system collected and performed by Machine Agents in MongoDB databases is online ordered by Multiagent System agent and saved in SQL data base. Ordering of data is done according to multilayer reference model of data integration earlier described. Such approach allows for archiving data collected by integrated monitoring systems and easy joining it with data describing orders managed by MRP/ERP system.

A demonstrator of the integrated manufacturing system is tested in laboratory conditions. In future it will be tested in semi production and production conditions. The aim of tests is verification and validation of proposed reference models and formulating more detailed requirements for integrated monitoring systems and in this especially systems based on multiagent technology.

\section{Implementation of integrated monitoring system in manufacturing conditions}

The idea of monitoring systems integration is tested on the base of developed demonstrator. Further research on development of a special system dedicated for interested manufacturing company are one of the results. A general concept of it is presented in Fig. 10. The aim of the system is integration of all information on the manufacturing level. Operator will have delivered all needed information about particular order, process documents, instruction and standards. Data to operator will be transferred from ERP integrated management system. However, also a management personnel through ERP system will have possibility to take on-line information about particular part production status, its quality, geometry dimensions, process and machine parameters and condition. Monitoring data will be automatically acquisitioned and processed by dedicated applications and devices operating according to Hard Real Time constrains. Currently this part of the system is based on dedicated sensors, special measurement cards and industry computer.

In the future it should be possible to use CyberPhysical-Systems to simplify it and to reduce its dimensions and implementation cost. It would allow for easier application and reconfiguration of the whole system. Monitoring part of the system is connected with data processing and integration module. Its aim is integration of data from process and machine monitoring with geometry measurement data. A special module is responsible for identification manufactured parts and identification of production documents. Every part will be signed by individual barcode to allow easy assign monitoring data to particular part in the data tree. The goal of documentation identification is to support machine operator in quick, automatic finding particular order in the IT system.

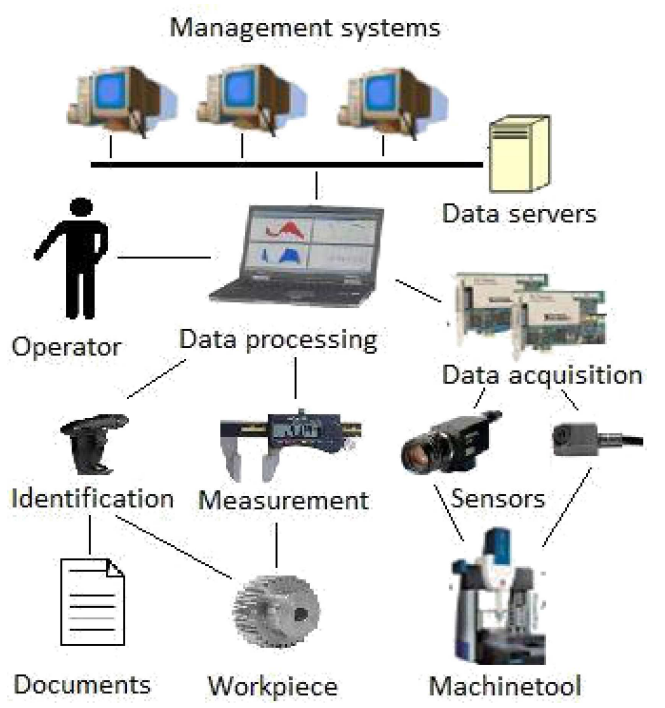

Fig. 10. General concept of the integrated monitoring system that allows for monitoring of machining process, machine tool, parts measurement and identification of parts and production documents.

Described application is a singular machine monitoring and integration module. It will operate as a part of the integrated monitoring system. According to multilayer reference model presented in Fig. 5 a system is responsible for integration of data from whole production process. A data describing machining operations performed on particular machine is integrated in the data structure built according to multilayer reference model presented in Fig. 6 .

System data base will be connected through special interface to integrated company management systems (MRP/ERP) and other company systems like CAD/CAM and process support applications. Data from integrated monitoring through the $\mathrm{MRP} / \mathrm{ERP}$ system could be transferred to systems of other companies in the frame of supply chain connected by $\mathrm{B} 2 \mathrm{~B}$ solutions.

\section{Conclusions}

Development of IT systems, machine control and advanced monitoring applications gives new opportunities for integration of production level with management systems. Number of advanced monitoring systems of discrete manufacturing process were developed during last years. However, as latest reviews show there are still lack of significant research ef- 
fort in the area of monitoring systems integration. There are also no common models or standards describing a way in which a monitoring systems should be build. Presented research were focused on preparing a concept of integrated monitoring system. Multilayer models were proposed to describe integrated monitoring system and data integration on the high abstraction level. Currently, as literature review shows there is lack of proper models that allow for structured ordering data from complex monitoring of production process, machines and parts. The aim of proposed models is to support development of proper IT system allowing integration of various distributed advanced monitoring applications. The demonstrator of integrated monitoring system was built according to models requirements. It's based on multiagent technology supported by client-server data management module. In the future Cyber-PhysicalSystems should be use to implement a lowest layers of the system. Application of CPS should allow for easy and inexpensive implementation of data acquisition and signals processing part of the system. It is the most specialized and because of it the most costly element of the system. In the demonstrator this part of the system is based on specialized application using Real Time software and hardware. Cyber-Physical-Systems implemented in this part of the system will have to operate according to Hard Real Time constrains as well. Moreover, it will have to fulfill requirements of work in the industrial environment because of operation close to machines, drives and machining process. The future research on integrated monitoring system are focused on development and improving multilayers models as well as implementation and testing demonstrator in semiproduction environment and further in production system.

Support by The National Centre for Research and Development of Republic of Poland - program INNOLOT, project "Advanced techniques of air plane gearboxes manufacturing - INNOGEAR", no INNOLOT/I/10/NCBR/2014.

\section{References}

[1] Oborski P., Transformation of production companies [in Polish: Przemiany zachodzace $w$ przedsiębiorstwach produkcyjnych], Inżynieria Maszyn, 17, 1, 7-16, 2012.

[2] Mason R., Lalwani C., Mass customised distribution, Int. J. Production Economics, 114, 71-83, 2008 .
[3] Coe N., Hess M., Global production networks, labour and development, Geoforum, 44, 4-9, 2013.

[4] Oborski P., Developments in integration of advanced monitoring systems, The International Journal of Advanced Manufacturing Technology, 75, 912, 1613-1632, 2014.

[5] Wang L., Wise-Shop Floor: an integrated approach for web-based collaborative manufacturing, IEEE Transactions on Systems, Man, and Cybernetics Part C: Applications and Reviews, 38, 4, 562-573, 2008.

[6] Nagalingam S., Lin G., CIM - still the solution for manufacturing industry, Robot Comput. Integr. Manuf., 24, 332-344, 2008.

[7] National Science Foundation, Cyber-Physical Syst., www.nsf.gov/funding/pgm_summ.jsp?pims_id=503286

[8] Park K.-J., Zheng R., Liu X., Cyber-physical systems Milestones and research challenges, Computer Communications, 36, 1-7, 2012.

[9] Wavering A.J., Foundation for Innovation: Strategic RED Opportunities for 21th Century CyberPhysical Systems, National Instution for Standardisation and Technology, Report January 2013.

[10] Yang L.R., Key practices, manufacturing capability and attainment of manufacturing goals: the perspective of project/engineer-to-order manufacturing, Int. J. Proj. Manag., 31, 1, 109-125, 2013.

[11] Herron C., Hicks C., The transfer of selected lean manufacturing techniques from Japanese automotive manufacturing into general manufacturing (UK) through change agents, Robotics and Computer-Integrated Manufacturing, 24, 524-531, 2008.

[12] Mourtzis D., Internet based collaboration in the manufacturing supply chain, CIRP Journal of Manufacturing Science and Technology, 4, 296-304, 2011.

[13] Oborski P., Directions of development of machining process monitoring [in Polish: Kierunki rozwoju zintegrowanych systemów monitorowania procesów obróbki skrawaniem], Mechanik, 8-9, 591-598/738, 2014.

[14] Van Veen-Dirks P., Management control and the production environment: A review, Int. J. Production Economics, 93-94, 263-272, 2005.

[15] Byrne G., Dornfeld D., Inasaki I., Konig W., Teti R., Tool Condition Monitoring - The Status of Research and Industrial Application, CIRP Annals, 44, 2, 541-567, 1995.

[16] Teti R., Jemielniak K., O'Donnell G., Dornfeld D., Advanced monitoring of machining opera- 
tions, CIRP Annals - Manufacturing Technology, 59, 717-739, 2010.

[17] Leitao P., Agent-based distributed manufacturing control: A state-of-the-art survey, Engineering Applications of Artificial Intelligence, 22, 979-991, 2009 .

[18] Oborski P., Integration of process and machine tool supervision on the base of advanced IT systems [in Polish: Integracja nadzoru procesu $i$ obrabiarki $w$ oparciu o zaawansowane systemy informatyczne], Mechanik, 8-9, 411-418/714, 2013.

[19] Karnouskos S., Colombo A.W., Architecting the next generation of service-based $S C A D A / D C S$ system of systems, Proc. of the 37th IEEE Annual Conf. on Industrial Electronics (IECON'11), Melbourne, Australia, 2011.

[20] ZuDe Z., Quan L., QingSong A., Cheng X., Intelligent monitoring and diagnosis for modern mechanical equipment based on the integration of embedded technology and FBGS technology, Measurement, 44, 1499-1511, 2011.

[21] Huismana M., Iivari J., Deployment of systems development methodologies: Perceptual congruence between IS managers and systems developers, Information \& Management, 43, 29-49, 2006.

[22] Desforges X., Archimede B., Multi-agent framework based on smart sensors/actuators for machine tools control and monitoring, Eng. Appl. Artif. Intell., 19, 6, 641-655, 2006.

[23] Mangina E., McArthur S., McDonald J., Moyes A., A multi agent system for monitoring industrial gas turbine start-up sequences, IEEE Transactions on Power Systems, 16, 396-401, 2001.

[24] Liu C., Li Y., Shen W., Integration of process monitoring and inspection based on agents and manufacturing features, Proceedings of the 2014 IEEE 18th International Conference on Computer Supported Cooperative Work in Design, pp. 208-213, 2014.

[25] Oborski P., Multiagent Shop Floor Control, Advances in Manufacturing Science and Technology, $34,3,61-72,2010$.

[26] Barbati M., Bruno G., Genovese A., Applications of agent-based models for optimization problems: A literature review, Expert Systems with Applications, 39, 6020-6028, 2012.

[27] Laplante P.A., Real-Time Systems Design and Analysis, John Wiley \& Sons, 2004.

[28] Oborski P., Man-machine interactions in advanced manufacturing systems, The International Journal of Advanced Manufacturing Technology, 23, 227232,2004 .

[29] Martinsena K., Holtskoga H., Larssona C.E., Social Aspects of Process Monitoring in Manufacturing Systems, 45th CIRP Conference on Manufacturing Systems, Proced. CIRP, 3, 567-572, 2012.

[30] Oborski P., Social-technical aspects in modern manufacturing, The International Journal of Advanced Manufacturing Technology, 22, 11\&12, 848-854, 2003.

[31] Mrugalska B., Needs for Safety Integration in Robust Design, Advances in Social and Organizational Factors, AHFE Conference, pp. 260-266, 2014. 